professional input, and the need to balance the roles of central government and local community. In James Nelson's essay on the second of these issues, the problem of popular bias against the mentally ill is discussed and it is commented that "Mental health care priority setting, to be done justly, must be done by people who see persons with mental illness with empathy and who are alive to broader concerns of social justice as well". It is then optimistically remarked "But to a large extent, these are dispositions that can be nurtured".

For those interested in the complex layers of scientific, ethical and economic problems which must be addressed if an equitable and effective and humane system of allocating resources to the care of the mentally ill is to be achieved, this book sets out and discusses the matrix of interweaving themes which must enter into a full and proper discussion. There is no attempt at some definitive, simplistic or scientifically specious solution. The interplay of fact and value is acknowledged and the necessary complexity of any decisiontaking process or procedure is recognised. This book provides a minimal conceptual vocabulary for any debate on these issues and salutary warnings about ignoring issues which must necessarily be addressed if any good outcome to such debate is to be achieved.

Those who have experienced at first-hand the recent reforms in the National Health Service in the UK will be heartened to learn that there is no one monopoly of vision contained in any chosen solution and that any attempted solution which vaunts one possible ingredient (for example market economics) above others is bound to produce incomplete and flawed results.

It is this reviewer's perspective that one of the great philosophical problems of our time in terms of its intrinsic interest and complexity as well as its practical importance, namely how health care resources should be allocated and by whom, has, in the UK, recently been shelved in favour of a crude and incomplete solution drawn from one discipline alone. That there is scope for a wider debate and a wider solution is evidenced by the contents of this book.

\section{AIDS and the Public Debate}

Editor-in-chief Caroline Hannaway, Amsterdam, IOS Press, 1995, 216 pages, $£ 60.00$

At first glance, AIDS and the Public Debate looks not unlike many other slim, expensive portmanteau collections of articles concerned with the history and medical sociology of AIDS. It is not. For between its covers one may find a series of papers written for the most part in an admirably off-the-cuff manner by several of the most important figures in the development of social and medical research policy-making in the United States, where more than half a million cases of AIDS have already been diagnosed.

Whilst this is not book of specialist medical ethics, it provides much valuable information concerning the ethical and other dimensions which have led to such varied and uneven patterns of the incidence and prevalence of HIV and AIDS. The courageous former Surgeon General of the United States, C Everett Koop, explains almost laconically how he was officially cut off from inner US government discussions of the epidemic for three and a half years after the announcement of the first cases in 1981. President Reagan was unable to utter the "A word" in public until April 1987, with consequences that are only too tragically apparent in American statistics - and human suffering.

Whilst there are no articles specifically concerned with the ethics of clinical trials, many contributors have important things to say about this important area. For example, the Director of the US National Institute of Allergy and Infectious Diseases (NIAID), Anthony S Fauci, describes from the inside the interactions between community-based AIDS activists and the leading institutions regulating American research policymaking. He concludes that after an early initial stage of confrontation, activists became an "invaluable resource" in developing better protocols, that were also more "userfriendly" for people living with HIV or AIDS. He also notes that the establishment of the parallel track mechanisms, pioneered by activists and scientists, had the great benefit of sustaining the necessary, rigorous testing process of new potential treatment drugs, whilst not forcing people into clinical trials against their will. In am similar vein the President of the Vaccine Division of Merck and Coळ inc describes in some detail the : emergence of an inter-company collaborative ethos within the US pharmaceutical industry.

Whilst it is widely fashionable $\frac{\bar{\sigma}}{\bar{\omega}}$. amongst some commentators to make lurid analogies between AIDS으 and the great plagues of world history, the distinguished medical histo- rian Allan M Brandt goes out of his. way to highlight the specificities of $\overrightarrow{\vec{\omega}}$ AIDS in the twentieth century - noto least in relation to ongoing debates about language and other forms of reporting and representation, observ- $\mathrm{N}$ ing that debates on such topics arenot simply about abstract semantics, but have real political significance in relation both to public perceptions ${ }^{\supset}$ and concrete policy-making. Like several other contributors, his analy- $\mathbb{D}$ sis goes some way to explaining why믈 demonstrably effective HIV/AIDS ฏิ prevention measures have themselves been so widely prevented, rather $\operatorname{than}_{\overrightarrow{0}}$ the transmission of HIV.

Sadly the non-American writings. about the international consequenceso of AIDS are of a uniformly lower le of analysis and significance. Indeed; it is very noticeable that the French and British contributions almost entirely lack any awareness of AIDS as an $\vec{F}$ epidemic, that is, as a large-scale을 human disaster. Thus Anne Marie Moulin restricts her analysis to the familiar and widely reported French scandal whereby 2,000 people, half of them haemophiliacs, were infected $\mathbb{D}$ through blood and blood products. $\frac{}{3}$ Yet we learn nothing whatsoever of: the way tens of thousands of cases of HIV infection in France related to the continuing governmental inability음 and/or refusal to respond to the desperate needs of injecting drug users, prisoners, and homosexuals. Not far below the surface of her article lies the $N$ familiar, distasteful notion of "inno- $N$ cent victims". The story she tells is? salutary and in many ways shocking, $\omega$ but it adds nothing to our understanding of why France has by far the mosto serious AIDS epidemic in Europe.

Writing of the voluntary sector response in the UK, medical historian $\square$ Virginia Berridge displays a similar innocence in relation to the direct $\vec{D}$

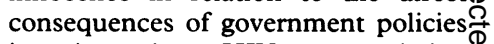
in increasing HIV transmission $\varnothing$ amongst those at greatest risk, namely gay men. She writes unpersuasively of a supposed "gay liberation agenda" at 
work in community-based HIV education for gay men, and confidently regards the Terrence Higgins Trust as a gay organisation - a description which the THT has consistently rejected since the mid-1980s. There is no sense here at all of AIDS as an issue of the greatest urgency, or of the extraordinary difficulties that have continuously faced those trying to develop effective and humane education in Britain for the constituency which continues to make up $80 \%$ of the AIDS mortality figures. AIDS and the Public Debate would thus have been a stronger book had the commissioning editors attempted to balance articles by US medical scientists with voices from American nongovernment community organisations, rather than an arbitrary coda of non-Americans, whose work adds little to our understanding of AIDS outside the USA, and tends to blur the focus of an otherwise valuable anthology.

SIMON WATNEY

The Red Hot AIDS Charitable Trust, Suite 32, The Eurowide Centre, 49 Effra Road, Brixton, London SW2 1B2

\section{Nursing Ethics. A Principle-based Approach}

\author{
Steven D Edwards, London, \\ Macmillan Press Ltd, 1996, 183 \\ pages, £11.99.
}

The intention stated by Steven Edwards is to produce a text on a principle-based approach to nursing ethics, comparable to the standard text on medical ethics by Beauchamp and Childress, ${ }^{1}$ which is less dense and therefore more accessible to students of ethics. He has succeeded admirably in these aims.

The approach, the principles themselves, and potential conflicts, as detailed by Beauchamp and Childress, are discussed. The text is well written; the discussion is lucid and orderly, rendering the work accessible to those with no previous knowledge of ethics. Arguments are clearly laid out, with easily identifiable premises and logical conclusions. In this regard, the text would be very useful to students learning the use of argument in health care ethics.
Although the author uses scenarios specific to nursing, many of these would be very familiar to junior medical staff - patients refusing treatment, the demands of the service requiring unpaid extra work, violence from patients and so on.

The contemporary challenges to "principle-ism" in nursing ethics have been summarised, the author concentrating on the approach developed from the work of Gilligan and Noddings, loosely referred to as a "care-based" approach. It is not entirely clear from the text that this challenge is not confined to nursing: there has been considerable debate about the merits of a principle-based approach over the past few years, the entire issue of the April 1990 fournal of Medicine and Philosophy providing a contemporary critique of bioethics. Clouser and Gert $^{2}$ (cited in the bibliography of the textbook) in this issue argue that "principles", as they are currently applied, serve purely as checklists of unrelated considerations, with no unifying theory within which to ground and relate these. To my mind, this is a serious charge against principle-ism, which any defence needs to acknowledge and take account of. It may be that the author felt this inappropriate to the target audience, but a brief outline of the wider context of this debate would have been helpful.

Additionally, Gilligan's thinking appears to have been misrepresented. Gilligan is said to have identified a focus on care in the moral thinking of females, "distinct from, and superior to, an allegedly male mode of thinking. ..." (page 132). My own understanding is that Gilligan ${ }^{3}$ herself claims that it is distinct, but not superior - mature individuals need to consider the voices of both care and justice. Neither does she claim that the care focus is exclusive to the thinking of females.

These reservations aside, the discussion of the care-based challenge as described here is thoughtful and well argued, the author concluding that principles can be applied in a manner which is "infused with care" (page 155). Further, in upholding a commitment to the primacy of the principles, he does not shrink from pointing out that there may be costs involved in so doing.

The author concludes the work by using the principle-based approach to consider the questions "what actions can be described as supererogatory", and "are nurses required to perform these". This is, I think, the first time I have seen this issue treated in this way in nursing ethics writing, and the discussion is timely in the light of the current climate within the UK health service. Again, much of the discussion would be meaningful to other health care professionals.

Overall, this is very worthwhile book to have on hand for those involved in teaching ethics to health care professionals, and a particularly useful textbook for students of nursing ethics.

\section{References}

1 Beauchamp TL, Childress JF. Principles of biomedical ethics [3rd ed]. Oxford: Oxford University Press, 1989.

2 Clouser KD, Gert B. A critique of principleism. Fournal of Medicine and Philosophy 1990; 15: 219-36.

3 Gilligan C. In a different voice: psychological theory and women's development. Cambridge, Mass: Harvard University Press, 1982.

JEAN HARBISON Department of Health and Nursing, Queen Margaret College, Edinburgh

\section{Of Life and Death. An Australian Guide to Catholic Bioethics}

\author{
Elizabeth Hepburn, North \\ Blackburn, Harper Collins \\ Publishers, 1996, 234 pages, \\ A $\$ 22.95$.
}

Dr Elizabeth Hepburn makes it clear in the preface to this book that readers need no specialist theological or philosophical studies, since it is not meant to be a comprehensive or scholarly work. It is, however, a valuable manual and a resource book of substance for teachers and nurse educators who would like to know the teaching of the Catholic Church on a wide range of controversial life and death issues in a reader-friendly form. The bulk of the book represents a development from lecture notes on ten biomedical topics given to student nurses.

Part one of the book begins with a brief and clear account of the main moral principles used for decisionmaking in biomedical ethics - justice, autonomy, beneficence and nonmaleficence. She gives a balanced 